\title{
INTEGRATING A SET OF LEAN CONSTRUCTION TECHNOLOGY TO BUILDING INFORMATION MODELLING
}

\author{
IhSAn Ali Hussein AL-SARray ${ }^{1 *}$, Yousif SAlam SAEEd ${ }^{* *}$ and Ahmed AdIL NaJi ${ }^{* * *}$ \\ *College of Engineering, University of Waist, Iraq and Don State Technical University-Russia \\ ** College of Engineering, University of Kirkuk, Iraq, and Don State Technical University-Russia \\ ${ }^{* * *}$ College of Engineering, University of Waist-Iraq
}

(Accepted for Publication: December 8, 2020)

\begin{abstract}
Technology has a great impact in managing and implementing highly desired complicate design construction projects, this paper attempted to address a set of synergies between Lean Construction Technologies (LCTs) and Building Information Modeling (BIM) to provide the researchers with a fully comprehensive idea about the impotence of the integration. Through reviewing and presenting of the published papers which presented the integration of one or two lean technology concepts integrated to building information modeling in accordance to the studied cases in one paper, this paper will provide the researcher, developer, and constructing companies with many studied cases presented some of the most important Lean technologies in this field. These technologies are; Last Planer System (LPS); KanBIM; VisiLean; Just-In-Time (JIT); Value Stream Mapping (VSM). Also, this paper suggested the possibility of integrating a $5 \mathrm{~S}$ technology to BIM for a future study.
\end{abstract}

KEYWORDS: Lean construction; Building Information Modeling; Integrating BIM to Lean construction techniques.

\section{INTRODUCTION}

T The conventional construction industry faces major challenges, but these problems can be minimized or solved by using new and efficient methods and techniques, such as LCTs and BIM (Sajedeh et al., 2016), to increase the performance of construction management and to produce better results in the project implementation process. Construction industry growing steadily required adoption of Lean and BIM as modern technology to enhance the performance measures of the construction industry (Gary and Larson, 2011), for example in 2016 The United States of America invested $\$ 712$ billion (6\% in value performance) and achieved noticeable increase about $13 \%$ financial profit (McCook and Dodge,2015). The use of this technology reduced errors and ihsanali@uowasit.edu.iq, yousif.salam@uokirkuk.edu.iq, ahmedadil@uowasit.edu.iq deletions in documents by $52 \%$, new business markets by $51 \%$, reducing the process of re-working by $48 \%$, new services by $46 \%$, reducing the work cycle time by $39 \%$, and employing or retaining employees by $23 \%$ (Zhang et al., 2018). As for the pre-fabricated models, the possibility of increasing productivity in the construction industry for health care projects the projects were that have adopted traditional methods of construction that the average waste metal ranges between $15 \%$ to $25 \%$ of the total of recycled minerals while projects which relied on BIM the percentage of metal waste was $5 \%$ to $10 \%$ of the total recycled minerals (Manisha, 2016). Currently, many companies around the world have embarked on adopting a synergy approach between BIM and lean construction in construction projects. The best example of this topic is Sutter Health and uokirkuk.edu.iq, a 
DPR construction cooperation, which relied on the concept of integration between BIM and lean construction within the Camino Medical Centre project in 2003, as well. The case concerning the Castro Valley project, which was characterized by the complexities and results achieved from the integration process. In the United Kingdom, the BIM and Lean Building integration approach has been used in several projects, most notably the Heathrow Terminal 5 project, Network Rail's Borough Viaduct project and the Highways Agency's Bidston Moss (Costain) and the M4/M5 Automation (Balfour Beatty) project which gave encouraging results on Using the integration approach (Dave et al, 2013).

Researchers and scientists acknowledged that BIM and Lean concepts have been stated and emphasized in the last two decades, but the integration process between Lean and BIM concepts has not been entirely exploited (Eroshkin et al., 2016), whereas the importance of each concept has been discussed in isolation from the other, numerous Studies have discussed the importance of using modern technologies in the construction industry, it is believable that these combinations between BIM and Lean will result in more successful results than using each principle separately in construction projects, in the United States of America the origin of this collaboration was initiated in the past two decades ( McCook and Dodge, 2015). The possibility of integrating these two concepts is determined by the nature of each of these concepts and their relation to a specific stage of the project. It is acknowledged that Lean construction is often associated with the construction phase itself, which can be carried out by applying many methods to optimize project activities, including eliminating unnecessary actions during project completion. As for the concept of information modeling of buildings (Zhang et al., 2018), it is closely connected with the preparatory phase for construction, which includes the stages of ihsanali@uowasit.edu.iq, yousif.salam@uokirkuk.edu.iq, ahmedadil@uowasit.edu.iq

${ }^{1}$ Corresponding author: College of Engineering, University of Waist, Iraq planning and design, which previous studies have confirmed that the use of information modeling of buildings will increase the efficiency of both design and planning phases of the project (Xingchen, 2019). It goes through the elimination of inconsistencies or errors that occur during the design of the construction project. The main principle of work on Lean construction technology is waste reduction, which includes (lost time, unnecessary measures, costs associated with unproductive activities, excess production with unnecessary information and material waste at the workplace) and at the same time an increase in the cost of the final product of the project, to satisfy the highest level of customer satisfaction (Zhang et al., 2018). While BIM methods provide a visual and multidimensional working platform for all participants in the completion of the project, which allows all the project participants to identify various existing constraints, as well as identify potential conflicts during construction that the project may encounter after completion, and since the development project is not only that applies to civil works, but also the group of architectural, mechanical and electrical works, etc. Thus, the BIM-Lean approach will effectively contribute to the creation and management of all architectural, civil, mechanics, plumbing, and electrical systems work as one integrated platform, as well as improve the effectiveness of their implementation. From the foregoing, it is clear that the integration of BIM with lean technologies will significantly contribute to the achievement of the basic principles of the proposed use of lean construction (Geetanjali, 2011).

The increasing importance of integrating BIM with Lean construction systems requires an expansion of research in this area and attempts to invent new technologies in the lean construction system, since there is a set of technologies used for this type of construction, which will be mentioned below, a section of 
these technologies that can be applied individually in project management, while researchers turned to another category of these technologies, which were applied in synergy with information modeling studies, but the problem is that these studies showed the use of only one or two types of these methods with building information modeling, but neglected the other technologies, this article tries to refer to what was previously published in this field in order to provide a full concept for integrating building information modeling with lean construction techniques that have been published in separate studies and try to collect them into One study that will help those interested in this novel method of the project management.

\section{BUILDING INFORMATION MODELING BIM}

It is very difficult to find a unified and accurate definition of building information modeling (BIM) because the definition depends mainly on the nature of the people who deal with this technology. At a time when the contractor considers BIM as a process, the designer defines it as a set of 3D models while researchers and specialists know BIM as a conceptual instrument used in construction (Allan, 2016). There are attempts to define this technology where it is possible to define the building information modeling as the creation of a digital model via a computer this model simulates in its detail the physical and functional characteristics of the structure, to enhance accuracy in the various construction phases of planning, design, construction, and operation. Also, BIM can be defined as a digital visualization instrument that contributes to increasing the communication between the architectural and engineering details of the building through the flow of a stream of unified information for all participants in the implementation of the project (Geetanjali, 2011).

The most acceptable definition is what the US ihsanali@uowasit.edu.iq, yousif.salam@uokirkuk.edu.iq, ahmedadil@uowasit.edu.iq

National Building Information Model Standard (NBIMS-US) suggested "Building Information Modeling (BIM) is a digital representation of the physical and functional characteristics of the facility. BIM is a common knowledge source for obtaining information about a facility that forms a reliable basis for decisions throughout its life cycle; defined as having existed since the earliest perception of demolition" (Xingchen, 2019). National Institute of Building Sciences (NIBS) defines building information modeling as a "digital representation of the physical and functional properties of the facility. As such it serves as a common knowledge source of information about a facility that forms a reliable basis for decisions during its life cycle from its inception onwards. It is defined as existing since the first conception of the demolition" (Manisha,2016).

This technology began to be used decades ago, but it has been significantly developed in the past 15 years and has become more acceptable and used by construction companies or organizations (Xingchen, 2019). Currently, BIM is an important technique in implementing projects, especially large and complex projects because it is It included passing information accurately from the design team to the creators and this leads to integration between the various building phases (Allan, 2016). The basic principles of building information modeling technology are design, estimation, construction process, building life cycle, performance, and technology, while the main function of BIM is to create a multi-dimensional digital model that includes 3D models (building models), 4D time, 5D cost, 6D operation, 7 D Sustainability and 8D Safety(Xingchen, 2019), and this is achieved through the use of a set of computer programs that collect data and process it to represent the characteristics of the real building. These characteristics may be material such as different building parts or properties such as cost estimation or structural analysis (Sacks et al., ${ }^{1}$ Corresponding author: College of Engineering, University of Waist, Iraq 
2010). Consequently, BIM is not just an instrument or a solution to a specific problem, but rather a scope of cooperation to increase the engineering value supported by smart digital data (Payam, 2019). The concept of building information modeling can be expressed in simple words is to create the building with all its properties actually before proceeding with its implementation on the construction site (Geetanjali, 2011).

\section{LEAN CONSTRUCTION}

According to (Dave et al, 2013) there are two main objectives of using lean construction in the construction industry, the first objective is to eliminate or reduce physical and temporal waste associated with project activities, the second main objective is to increase the generated engineering value in proportion to the client requirements. Researchers have pointed out many definitions of Lean construction, which are most similar in terms of focusing on what lean construction is, Lean construction can be defined as a way to achieve a balance between human and other resources, which leads to lower costs, elimination of waste and contributes to the timely implementation of the project. It is an ongoing process to meet the highest levels of customer satisfaction and value. The history of Lean's production concept dates back to the research conducted by the Japanese Toyota Motor Company, which took a new approach in the industry, known as the Toyota Production System (TPS) (Vidhate and Salunkhe, 2018), where the main focus of this system was on increasing productivity and reducing waste, and as a result of these historic assets, Lean construction can be identified. the practical application of Lean principles of production in a building environment, but the difference between the production environment and the building environment should be taken into account because of the problems and ihsanali@uowasit.edu.iq, yousif.salam@uokirkuk.edu.iq, ahmedadil@uowasit.edu.iq

${ }^{1}$ Corresponding author: College of Engineering, University of Waist, Iraq characteristics that constitute a construction project that ultimately produces complex results.

Lean thinking is the new management style that this model developed in the early nineties, when researchers became aware of a new concept called lean thinking or lean construction, using lean manufacturing tools and techniques in building management processes, noticeably minimized waste associated with project activities (Suchun, 2019), which has a positive impact on the engineering value of the project and the reduction of costs and time required for its completion. Lean thinking considered the project as a single event, then all its parts and components should be connected so that information flows clearly between successive phases of the project and also between participants in the actual implementation of the project. Lean construction has basic principles that are the basis for the work of all the techniques and methods of this concept (Payam, 2019).

Several principles have evolved through Lean concepts, which are the concept of flow and the concept of value, and these principles have been reliably connected, some of these principles are very basic, while the others are more applied. Lean thinking was adopted primarily based on the concept of flow, and then merged with it after a period of the concept of value, which was the result of the quality evolution through the integration of these two concepts, a set of principles were depended in construction projects or industrial projects to achieve the basics of Lean thinking, which is a philosophy, process, customers and partners, as well as problem solving, the most of these principles are the followings: Limitation of non-value activities; Deliverable achieved as per client's requirements; Reduced variability; Reduced cycle times; Simplify any complex bits yet maintaining quality; Flexibility in deliverables; Transparent process; Maintain control through the whole process; Continuous improvement made in the 
process; Improved flow balance with improved conversion; Benchmark (Sacks et al., 2011). (Barathwaj et al., 2017).

\section{BIM INTEGRATED WITH LEAN CONSTRUCTION}

As a result of the development of the construction industry, new technologies and concepts have emerged that have contributed to the development of this industry and increase its productivity. One of these concepts is the building information modeling (BIM). However previous studies agreed that the use of Lean construction methods helped to improve the quality and cost of construction, while BIM is a complex intellectual tool that contributes to building products, and although lean construction and BIM are independent of each other, studies have confirmed that integrating these two concepts have excellent results in reducing waste and increasing performance (Sacks R, 2010). Researchers have identified 56 interactions between the two concepts based on empirical data, and despite this interaction, this number cannot be considered final and may increase due to increased research and development in this field of knowledge. Integration can be divided between BIM and Lean construction, overall application value, and partial value since the total value indicates the use of the full Lean construction properties and the full BIM capabilities at all stages and disciplines of the construction project (Manisha 2016). The process of synergy and integration between Lean construction and BIM is mandatory, as this integration changes the coordination of the management team during the Implementation process, which affects the final quality of work. Based on this, lean construction and information modeling of buildings should be applied based on one concept, but, despite this importance, the lack of systematic research to describe this interaction, which requires additional efforts to fill this gap (Ocheoha and Moselhi, 2013).

The use of BIM contributes to improving the construction process due to the ability of this technology to reduce the project construction process wastes, whether waste resulting from unnecessary activities or a waste of time and therefore the removal or reduction of waste is one of the main goals of lean construction, that BIM is Technology based on focusing on individuals and processes, as well as the case with lean construction, as the theoretical concept of it also focuses on individuals and processes. Therefore, the technological ability to BIM and the theoretical basis for lean construction complement one another. Based on the foregoing, the synergy process between these two concepts will lead to better results for the construction (Sajedeh et al., 2016]

The application of BIM technology and through the creation of smart digital models that can simulate the actual properties of the construction and this generates accurate tables for the time required to implement the project activities or what relates to the estimated costs of the activities. Also, BIM helps to detect future clash between the activities and thus This clash can be avoided and it also makes the design clear and understandable to all participants in the implementation process, which increases the cooperative value among all teams, as has been proven through practical application that BIM reduces uncertainty during the entire construction process and thus facilitating the process of meeting customer requirements. These capabilities provided by BIM technology lead to reduce or remove waste and support productivity during the construction process and this in turn leads to the formation of a hypothesis that the application of BIM in the construction process makes it a lean construction process (Payam, 2019). 
According to (Dave et al., 2013), four main mechanisms explain the importance of this integration:

BIM contributes directly to Lean's goals: Waste removal and productivity development, which was adequately explained within the integration process between BIM and lean construction an example of this is the detection of any conflict at the design stage. This is a BIM function where any collisions or conflicts between architectural, structural, or other disciplines are checked and thus designers can fix problems. This issue saves a lot of time and money that could be lost during the redesign and this is the most important goal of lean production. in terms of minimizing waste and developing value, for this all stakeholders must be involved in the project at an early stage.

BIM allows Lean and indirectly helps achieve Lean's goals: collaborative planning is one of Lean's core technologies, and the basic principle of collaborative planning is to gain a deeper understanding of pre-planned activities, as designers test different working methods to determine the best way fulfillment and improvement of the construction task using BIM tools, where the 3D model is connected with the project plan and simulate events for a certain period, which gives the team a deep mutual visual understanding compared to using 2D plans.
Assistive information systems provided by BIM contribute to Lean's goals: These models perform complex and useful numerical calculations that were cumbersome and very erroneous, using previously $2 \mathrm{D}$ diagrams.

Lean technologies facilitate the implementation of BIM: Although the nature of the Lean construction environment focuses on predictability, but also focuses on collaboration and experimentation, it facilitates the introduction and implementation of BIM technologies and increases their effectiveness. This issue is especially important when adopting an initial strategy for a new technology that has been used recently during the project life cycle (Dave et al., 2013).

\section{LEAN CONSTRUCTION TECHNIQUES}

There are many methods and techniques to achieve the basic principles of Lean construction, which are to reduce waste and increase labor productivity, and despite the existence of these technologies, it is possible that subsequent studies can add new methods and techniques. Some of these methods can be used individually in construction, while others have been used integrally with BIM. some of Lean methods and techniques are listed in table 1 below:

Table (1): Lean methods and techniques.

\begin{tabular}{|c|c|c|c|c|}
\hline \multirow[t]{2}{*}{ No. } & \multirow[t]{2}{*}{ Lean methods and techniques } & \multirow[t]{2}{*}{ Abbreviation } & \multicolumn{2}{|c|}{ Technique used } \\
\hline & & & Separately without BIM & Integrating with BIM \\
\hline 1 & Just in Time. & JIT & $\checkmark$ & $\checkmark$ \\
\hline 2 & Total Quality Control. & TQC & $\checkmark$ & \\
\hline 3 & Total Productive Maintenance. & TPM & $\checkmark$ & \\
\hline 4 & Employee Involvement. & El & $\checkmark$ & \\
\hline 5 & Continuous Improvement. & $\mathrm{Cl}$ & $\checkmark$ & \\
\hline 6 & Time-Based Competition. & TBC & $\checkmark$ & \\
\hline 7 & Concurrent Engineering. & CE & $\checkmark$ & \\
\hline 8 & Value-Based Strategy (or & VBS / VBM & $\checkmark$ & \\
\hline
\end{tabular}

ihsanali@uowasit.edu.iq, yousif.salam@uokirkuk.edu.iq, ahmedadil@uowasit.edu.iq

${ }^{1}$ Corresponding author: College of Engineering, University of Waist, Iraq 


\begin{tabular}{|c|c|c|c|c|}
\hline & management). & & & \\
\hline 9 & Visual Management. & VM & $\checkmark$ & \\
\hline 10 & Re-engineering Method & $\mathrm{RM}$ & $\checkmark$ & \\
\hline 11 & Last Planner System. & LPS & $\checkmark$ & $\checkmark$ \\
\hline 12 & Daily Huddle Meetings & $\mathrm{DHM}$ & $\checkmark$ & \\
\hline 13 & The Kanban System. & KS & $\checkmark$ & \\
\hline 14 & Value Stream Mapping. & VSM & $\checkmark$ & $\checkmark$ \\
\hline 15 & $\begin{array}{l}\text { Plan Conditions and Work } \\
\text { Environment in the Construction } \\
\text { Industry. }\end{array}$ & PCMAT & $\checkmark$ & \\
\hline 16 & $\begin{array}{l}\text { 5s Process (set in order, Sort, } \\
\text { Shine, Standardize, Sustain) } \\
\text { addresses transparency. }\end{array}$ & $5 S P$ & $\checkmark$ & $\checkmark$ \\
\hline 17 & KanBIM (Kanban using BIM). & KANBIM & & \\
\hline 18 & VisiLean & VISILean & & \\
\hline
\end{tabular}

Some of the Lean techniques that have been used integrally with BIM are including the followings:

\subsection{Last Planner System (LPS):}

Last Planner System LPS is the integration process of BIM and one of the lean building approaches, which is the, creates an effective system for building products, as one of the most important elements of the LPS is the turnkey readiness process, which includes the elimination of preconditions, which leads to transfer tasks to workable accumulation and then is included in the weekly action plan. The integration process with building information modeling facilitates the process of visualization of activity and the sequence of their study. This issue not only develops project planning but also the final product by reducing reformulation processes or studying recurring problems. In some projects where LPS have been applied, it has been noticed that this method is being associated with many problems or obstacles that are listed below:

1-lack of a systematic analysis of the limitations of certain types of activities and focus on the preparation of the entire plan.

2-progress reports are being prepared, but the focus is not on the reasons or tools for continuous development.

3-less cooperative approach to planning.

4-problem of information flow from short-term plans, such as (Look-ahead plans) to long-term plans, such as (phase, master plans) for monitoring and tracking.

5 - All LPS elements have not totally deployed.

These problems can be mitigated through the use of BIM, as it will support a system in which models are constantly updated throughout the life of the project. BIM-models with integrated information might provide an easy flow of information between different levels of planning. BIM, which contains different levels of detail, integrating it with different levels of the latest planning system (LPS), will create a unification system, with the implementation of all elements of the latest planning system, which could be significantly improved (Dave et al., 2013).

\subsection{KanBIM (Kanban using BIM)}

The Kanban technology is an effective knowledge to ensure the minimum resources needed to implement measures, depending on the actual needs, for waste reduction, of the process that accompanies construction work, this technique also offers a storage topic solution.

ihsanali@uowasit.edu.iq, yousif.salam@uokirkuk.edu.iq, ahmedadil@uowasit.edu.iq ${ }^{1}$ Corresponding author: College of Engineering, University of Waist, Iraq 
This solution allows you to efficiently manage the production flow and thereby reduce sources waste, such as (moving operators, waiting times, storage) (Vidhate and Salunkhe, 2018). The term KanBIM refers to the principles of Lean construction using BIM (Kanban using BIM), which is a management system that contains programs, mechanisms, and devices that support Lean work movement in the workplace, this facilitates short-term work planning, and also monitoring, providing a clear vision of tasks ready for implementation, planned activities and the current working situation (Sacks et al., 2010). The KanBim concept aims to use detailed information from existing products in building information models to ensure accurate coordination of operations at construction sites. It is based on local business plans and a process planning methodology. Three main factors required the creation and development of this system:1-to facilitate the procedural and organizational changes necessary for long-term implementation, by the latest planning system (LPS).2-The process integration between Lean construction and BIM has produced many areas in which the high quality of product information provided by the information models has a significant impact on the development of the workflow at the construction site, and this occurs as a result of reduction of waste resulting from redesign or lost time, as well as through the effective management of materials in place.

3-previous studies have given encouraging results on the creation of interfaces that are model-dependent in providing effective visual perception to describe the current and future status of operations associated with project activities, and that the use of these interfaces has had a significant impact on Lean construction applications.

\subsection{VisiLean}

The VisiLean system is a production management system that has used for scheduling, planning, and monitoring processes to monitor ihsanali@uowasit.edu.iq, yousif.salam@uokirkuk.edu.iq, ahmedadil@uowasit.edu.iq

${ }^{1}$ Corresponding author: College of Engineering, University of Waist, Iraq obstacles or constraints for project activity resources. The process of integrating the BIM model into the system itself contributes to providing a concurrent perception of the system that the VisiLean system has evolved as a research program to, enhance the integration between building information modeling and Lean construction, and it helps to import master plans from other programs such as Primavera. The VisiLean system supports the work of the Last Planner System in all its units such as (weekly planning, phase) where conflicts are marked in the allocation of materials for users as an example, the green color is given to the direct activities in it while the red color is given to the activities planned to be implemented, in this case, the movement and the flow of materials between activities is known, and therefore it is possible to monitor any inconsistency or use the same sources for more than one activity. The VisiLean system here is not intended to replace the human effort in the Last Planner System (LPS) but rather supports it. The VisiLean system relies on visual management such as Kanban through direct support for the work of the Last Planner System (LPS) and in a visual way, depending on the BIM window. This is one of the most important VisiLean elements, where production is managed through one interface, which contributes to visualizing production stages in any period of the life of the project, in addition to improving the production situation (Phuong and Reza, 2019).

Value Stream Mapping is the most useful tool for lean construction, and it can be defined as a paper and pencil tool, which depends on the display of plans and symbols to represent production processes in the building. The mechanism of operation of this technology is described based on a complete analysis of the current workflow and identification of multiple wastes associated with the project activity, and then disposal of these wastes to obtain a future

\subsection{Value Stream Mapping (VSM)}


state, and based on the foregoing, we can conclude that the technology for Value Stream Mapping is based on the two main elements (current case) is the scenario of the working case according to the original work schedule, and after analyzing this case and determining the quality of the waste present in eating and deleting it, the workflow goes over to another case, called (future case), and this case is considered as the result of the improvement and development process that was done on the old working case by using modern tools and methods, therefore (future case) should reflect the uninterrupted progress of work and the flow of materials and resources between the stages of production (Barathwaj et al., 2017).

A set of previous studies shows that the process of interfacing or integration between BIM and VSM helped to improve the future state of value stream technology, as this integration provided more flexible and overlapping interaction in the collection and exchange of information between various stakeholders in the project, especially when using building information modeling is at the design stage, where it provides a seamless information flow between different groups (civil, mechanical, electronic, etc.) where individual information models are created that ultimately combine into one central model and thus give way to all specialties in the field of remuneration, making adjustments or additions to the general and real design instead of experimenting with repetitive ones operations, delivery of late data and loss of time, as well as allowing the owner or organization to provide the desired Notes or adjustments at the design stage and avoiding subsequent spare orders The basics that lead to loss of time and additional costs (Barathwaj et al., 2017)..

\subsection{Just-In-Time (JIT)}

This is one of the lean building technologies and the philosophy of this technology is aimed at reducing or eliminating the storage operations of ihsanali@uowasit.edu.iq, yousif.salam@uokirkuk.edu.iq, ahmedadil@uowasit.edu.iq

building materials involved in the implementation of project activities and making supplies limited by the time specified for the implementation of this event and ensuring the flow of materials without interruption, this business leads to higher quality when implementing the project and reducing the resulting waste from warehouse operations, which may be subject to aging or damage, it also helps It's possible to use the space allocated for the project, especially in confined spaces or in overpopulated cities, that the Just On Time (JIT) technique does not require an increase in costs but requires training in the reorganization of work, and therefore this technology has measurable benefits as well as immeasurable benefits.

Using BIM has a positive effect on both types of benefits. In terms of measurable benefits, building information modeling helps to improve the quantitative measurement of materials using accurate digital calculations that can be updated at any time and easily. As for the immeasurable benefits, BIM is a visual perception that helps in communication and cooperation between shareholders during the implementation of the project and suppliers of building materials, suppliers of building materials, the quantities calculated based on two-dimensional features are exaggerated and contain many estimation errors or unintentional deletions and further The process of inaccurate calculation of volumes of building materials is a waste of time and an increase in cost factors. The positive impact of BIM and (JIT) technology integration can be briefly described below.

Inventory Reduction: The process of reducing stocks of building materials has a direct impact on the development of productivity by reducing the risk of theft or damage, space use, reducing storage costs, as well as financial costs, and the use of BIM provides a large number of quantitative calculations with high accuracy, as well as automation of the building model. ${ }^{1}$ Corresponding author: College of Engineering, University of Waist, Iraq 
Improved Quality: The purpose of using JIT technology is to eliminate defects in building materials. BIM can prepare data with details of high-quality materials, and can also be used in quality control.

Visualization: Visual management of building materials will improve communication between project implementers and material suppliers, and this will reduce the presence of waste, whether it be waste resulting from damage to building materials or other types of waste that include change orders (Ocheoha and Moselhi, 2013).

\section{FUTURE RESEARCH OF 5S TECHNIQUE WITH BIM}

5s technology is Lean construction technology that is used to develop the work environment and increase productivity, as this technology focuses on optimal site management, as well as human effort and capital, and helps to remove waste associated with project activities, the 5S system used in construction is technology based on Toyota's Japanese site management system, where the original Japanese terms have been replaced by the English equivalent $\mathrm{m}$ language as shown below.

- Set in order (Seiton)

-Sort (Seiri)

- Shine (Seiso)

-Standardization (Seiketsu)

- Sustain (Shitsuke)

At the first stage, a group of activities is identified, then at the second stage it is determined what is necessary or not necessary from these types of activities, and at the third stage it is a question of reviewing and checking for waste disposal from these types of activities, then the transition to the fourth stage, which it is a group work stage to unify the method of work since the fifth and final stage requires compliance with the criteria agreed upon at the previous stage [18]. By referring in this research

to $5 \mathrm{~S}$ technology as future development, ihsanali@uowasit.edu.iq, yousif.salam@uokirkuk.edu.iq, ahmedadil@uowasit.edu.iq

${ }^{1}$ Corresponding author: College of Engineering, University of Waist, Iraq researchers can conduct some methodological and practical research on the integration of $5 \mathrm{~S}$ technology with BIM to achieve the construction project management with better productivity and reduce waste associated with different activities. The development process can be accomplished by creating a 4D model using one of the computer software and then applying the basic stages followed in this technology. For example, it is possible to define in the first stage a set of project activities according to the work progress schedule and in the second stage, the necessary or unnecessary activities are identified For these activities to complete the process of removing waste and unnecessary activities in the third stage, while in the fourth stage, common standards of all specialties (civil, electrical, mechanical, etc.) must be established to develop and update the model after removing the waste Thus, the transition to the fifth stage in which commitment and application of this system are applied to the rest of the project activities (Ajaya amd Sridharb, 2016).

\section{CONCLUSION}

The traditional building methods have become unable to complete projects within the optimal time and cost limits, therefore, there is a need to rely on modern techniques and ideas that contribute to increasing productivity and reducing waste, including what was covered in this research, namely BIM and lean construction, two of the concepts known in the construction industry, where previous research studies emphasized the importance of complementarily between these two concepts and that the integrated approach has led to better results. Lean construction technologies aim in their entirety to improve the quality of performance through a set of procedures, including those related to the worksite, increase cooperation between all project teams, reduce or remove unnecessary activities, as well as concerning 
information flow. As for BIM, it provides a unified digital platform and smart and flow Interactive information allows lean technologies to achieve the required quality, that is why it is considered the integration between these two concepts is necessary for eliminating many problems in the construction industry. In this research, both the concept of BIM and lean construction were defined, as well as the basic principles of lean and the importance of its integration with BIM, as well as the most important different techniques of lean construction were mentioned, but the focus was placed only on some of the techniques that were used with BIM which were mentioned in previous researches and the research also provided a research look Futures in the field of increasing integration by incorporating new ideas for lean construction with BIM. As the researchers could not find any data on the use of the concept of integration between BIM and lean construction concerning construction projects in Iraq in general or Kurdistan Region projects in particular, it is recommended to embrace such technology to overcome the traditional method of management and to achieve the benefits of integrating BIM to Lean technology.

\section{REFERENCES}

Ajaya R., Sridharb M.B. (2016). INCORPORATION OF $5 \mathrm{~S}$ METHODOLOGY IN CONSTRUCTION PRACTICES Int. J. Chem. Sci.: 14(S1), 127-134.

Allan F. O. (2016). Interaction between Lean Construction and BIM. Master's thesis. [Online] Available: https://www.diva-portal.org/smash/get/diva2:1 048993/FULLTEXT01.pdf

Barathwaj R., Singh R.V., Gunarani G. I. (2017). Lean Construction: Value Stream Mapping for Residentials Construction. IJCIET, 8, 1072-1086.

ihsanali@uowasit.edu.iq, yousif.salam@uokirkuk.edu.iq, ahmedadil@uowasit.edu.iq

Dave, B., Koskela, L., Kiviniemi, A., Owen, R.,and Tzortzopoulos, P. (2013). Implementing Lean in construction: Lean construction and BIM. London, UK: CIRIA.

Eroshkin S.Y., Kallaur G.Y., Papikian L.M. (2016) Lean Construction, and BIM: Complementing Each Other for Better Project Management. Review of Business and Economic Studies. 4(4):17-22.

Geetanjali Ningappa. (2011). "Use of Lean and Building Information Modeling (BIM) in the Construction Process; Does BIM make it Leaner." (Master's thesis).

Gray C., Larson E. (2011), Project Management, McGraw-Hill/Irwin, Boston, MA, USA, 5th edition,

Manisha G. (2016). INTEGRATION OF BUILDING INFORMATION MODELING (BIM) AND PREFABRICATION: A BOOST TO LEAN PRINCIPLE ENVIRONMENT. Master's thesis submitted to the North Dakota State University of Agriculture and Applied Science. [Online] Available: https://pdfs.semanticscholar.org/9c7c/fba1ca52 12880747cb49681f963316a4b893.pdf"9

McCook K., Dodge D. (2015). Analytics (2010-16) Outlook for, U.S. Construction Presentation, Dodge, Auburn Hills, MI, USA,

Ocheoha I. A., Moselhi O. (2013). Impact of Building Information Modeling on Just-In-Time Material Delivery, ISARC 2013 - 30th Int. Symp. Autom. Robot. Constr. Mining, Held Conjunction with 23rd World Min. Congr. 793-801 (2013)

Payam F. L. (2019). BIM in Construction Management: Leaning the Design-Bid-Build (DBB) Project Delivery System by Using BIM in Design Phase. Master's thesis. [Online] Available: https://webthesis.biblio.polito.it/11622/"/

Sacks R, Koskela L, Dave BA, Owen R. (2010). Interaction of lean and building information modeling in construction. J Constr Eng Manage. 136(9), 968-980. ${ }^{1}$ Corresponding author: College of Engineering, University of Waist, Iraq 
Sacks, R., Barak, R., Belaciano, B., Gurevich, U. \& Pikas, E. (2011), Field Tests of the Kanbim ${ }^{\mathrm{TM}}$ Lean Production Management System' In: Rooke, J. \& Dave, B., 19th Annual Conference of the International Group for Lean Construction. Lima, Peru, 13-15 Jul 2011.

Sacks, R.; Radosavljevic, M.; Barak, R. (2010). Requirements for building information modeling based lean production management systems for construction. Autom Constr. 19, 641-655.

Sajedeh, M., Fleming, A., Talebi, S., and Underwood, J., 2016. Development of an Experimental Waste Framework Based on Bim /Lean Concept in Construction Design. In 24th Annual Conference of the International Group for Lean Construction

Suchun Y. (2019). APPLICATION OF BIM DURING LEAN CONSTRUCTION OF HIGH-RISE BUILDINGS. THE CIVIL ENGINEERING JOURNAL, 27(3).

Vidhate, T., \& Salunkhe, A. A. (2018). A general overview of lean management in the construction industry. International Journal of Engineering and Technology (IRJET), 5(7), 1999-2004.

Zhang X, Azhar S, Nadeem A, Khalfan M. (2018). Using building information modeling to achieve lean principles by improving the efficiency of work teams. Int J ConstrManage. 18(4),293-300.

Phuong N., Reza A. (2019), Synergistic Effect of Integrated Project Delivery, Lean Construction, and Building Information Modeling on Project Performance Measures: A Quantitative and Qualitative. Hindawi, [Online] Available: https://doi.org/10.1155/2019/1267048

Xingchen Z. (2019). Integrating Lean Construction, BIM, and Quality: A New Paradigm for the Improvement of Chinese Construction Quality. Doctoral dissertation. [Online] Available: https://researchportal.bath.ac.uk/en/studentThe ses/integrating-lean-construction-bim-and-qual ity-a-new-paradigm-for

ihsanali@uowasit.edu.iq, yousif.salam@uokirkuk.edu.iq, ahmedadil@uowasit.edu.iq ${ }^{1}$ Corresponding author: College of Engineering, University of Waist, Iraq 